\title{
Fatores Associados ao Aborto Espontâneo Recorrente
}

\author{
Recurrent Spontaneous Abortion-associated Factors
}

\begin{abstract}
Ricardo Barini ${ }^{1}$, Egle Couto ${ }^{1}$, Marcos Matias Mota ${ }^{1}$, Carolina Taddeo M. dos Santos ${ }^{1}$,
\end{abstract} Sofia Rocha Leiber ${ }^{2}$, Simone Cotes Batista ${ }^{2}$

\begin{abstract}
RESUMO
Objetivo: identificar fatores mais freqüentemente associados ao aborto espontâneo recorrente. Casuística: no periodo de março de 1993 a março de 1997, 175 pacientes foram avaliadas no Ambulatório de Aborto Recorrente do CAISM/UNICAMP. Os critérios de seleção foram: história de três ou mais abortos espontâneos consecutivos em pacientes com idade inferior a 35 anos e/ou dois abortos e idade superior a 35 anos.

Métodos: o protocolo de investigação incluiu: cariótipo; histerossalpingografia; dosagem seriada de progesterona e/ ou biópsia de endométrio; pesquisa sorológica de infecções: toxoplasmose, listeriose, brucelose, sifilis e citomegalovírus e pesquisa para Mycoplasma hominis e Chlamydia trachomatis na secreção cérvico-uterina. A investigação também incluiu dosagem de hormônios tiroideanos e da glicemia de jejum; pesquisa de fator auto-imune por meio de painel de autoanticorpos; pesquisa de fator aloimune mediante anticorpos contra antigenos leucocitários humanos (anti-HLA), prova cruzada por microlinfocitotoxicidade e cultura mista unidirecional de linfócitos, em que se comparam as respostas maternas diante das células paternas e de um doador nãorelacionado para pesquisa de fator inibidor destas respostas no soro materno. O exame dos parceiros incluiu: exame fisico geral e especial, sorologias para sifilis, doença de Chagas, hepatite $B$ e $C$ e sindrome da imunodeficiência adquirida (AIDS), além da prova cruzada por microlinfocitotoxicidade e da cultura mista de linfócitos.

Resultados: o fator mais freqüentemente encontrado foi o aloimune (86,3\% dos casos), representado por prova cruzada negativa e inibição na cultura mista de linfócitos inferior a $50 \%$. O segundo fator mais freqüentemente encontrado foi a incompetência istmo-cervical $(22,8 \%)$, seguido pelo fator hormonal $(21,2 \%)$, representado principalmente pela insuficiência lútea. Algumas pacientes apresentavam mais de um fator concomitantemente.

Conclusão: para uma investigação completa dos fatores associados ao aborto espontâneo recorrente faz-se necessária a inclusão do fator aloimune, sem a qual a maior parte dos casos não terá etiologia esclarecida.
\end{abstract}

PALAVRAS-CHAVE: Aborto recorrente. Anticorpos antifosfolipides. Linfócitos. Incompetência istmo-cervical.

${ }^{1}$ Departamento de Tocoginecologia da Faculdade de Ciências Médicas da Universidade Estadual de Campinas (UNICAMP)

${ }^{2}$ Laboratório de Cultura de Tecidos do HEMOCENTRO da UNICAMP

Correspondência:

Ricardo Barini

UNICAMP/ Assessoria Técnica e Científica do CAISM

Rua: Alexander Fleming, 101 - Cidade Universitária

"Zeferino Vaz"

13083-970 - Campinas - SP

Fone: (19) 788-9402 Fax: (11) 289-5935 e 289-3687

e-mail: barini@turing.unicamp.br

Bolsa de Iniciação Científica para Marcos Matias Motta e Carolina Taddeo M. dos Santos (CNPq)

\section{Introdução}

Dá-se o nome de aborto espontâneo recorrente (AER) à história reprodutiva de três ou mais abortos sucessivos espontâneos, situação relativamente comum e que representa um desgaste emocional na vida de uma mulher. O termo também se aplica quando se observam dois abortos em pacientes com idade superior a 35 anos $^{1}$. Vários têm sido os fatores associados à ocorrência de AER. Desde a Antigüidade, a ciência procura conhecer melhor a etiologia desta entidade, bus- 
cando alternativas terapêuticas que possam produzir melhores resultados gestacionais. Entretanto, em aproximadamente metade dos casos de AER, a etiologia permanece desconhecida ${ }^{2}$, sugerindo a necessidade de novos caminhos para sua elucidação.

A Imunologia moderna tem apresentado novos recursos, com possibilidade de esclarecimento de casos em que a investigação habitual não chega a qualquer conclusão. A busca da identificação de anticorpos que podem estar relacionados com perdas recorrentes tem gerado esperanças de que muitas destas mulheres possam ser adequadamente investigadas, diagnosticadas e tratadas.

Estima-se que a taxa de perdas precoces entre as gestações clinicamente reconhecidas esteja entre 12 e $15 \%^{3}$, afetando cerca de $2 \%$ da população em idade reprodutiva ${ }^{4}$. O risco de que a próxima gestação termine em perda aumenta de forma gradativa quando o aborto se repete. Em mulheres que já tiveram dois abortos sucessivos, a probabilidade de um terceiro varia de 17 a $35 \%$, e para aquelas que já passaram por três ou mais abortos, a probabilidade de ocorrência do quarto está entre 25 e $46 \%{ }^{5}$.

Diversos fatores estão associados ao aborto recorrente. Entre eles estão os anatômicos, endócrinos, genéticos, infecciosos e imunológicos.

Csapo et $a .^{6}$ mostraram que a insuficiência de corpo lúteo pode ser causa de perdas conceptuais precoces. A baixa produção de progesterona com a maturação endometrial insuficiente para suportar a nidação e o desenvolvimento do ovo foi sugerida como mecanismo destas perdas ${ }^{7}$.

Não há consenso a respeito dos critérios de diagnóstico dos defeitos da fase lútea. A dosagem de progesterona sérica tem os inconvenientes de sua ampla variação devido ao caráter pulsátil de sua produção e de não revelar a responsividade endometrial $^{8}$. A biópsia de endométrio tem sido o método mais acreditado para o diagnóstico ${ }^{9}$.

Causas genéticas também têm sido apontadas para o aborto recorrente. Boué ${ }^{10}$. identificou translocações balanceadas em $7,2 \%$ dos casos.

Os defeitos anatômicos do útero são tidos como possiveis causas de aborto recorrente. Incluem-se a incompetência istmo-cervical, septos uterinos, miomas e sinéquias. A participação destes defeitos no aborto recorrente é estimada entre 15 e $27 \%^{1,11}$.

As infecções maternas por alguns agentes, como Chlamydia trachomatis, citomegalovírus, Toxoplasma gondii, Mycoplasma hominis e Listeria monocytogenes, foram relacionadas ao aborto único, mas não ao aborto recorrente ${ }^{12}$.

A investigação da presença de autoanticorpos maternos associados ao aborto recorrente tem adquirido importância crescente na avaliação destas pacientes, principalmente no que se refere aos anticorpos antifosfolipides ${ }^{2}$.

O objetivo deste estudo foi avaliar a freqüência de fatores associados ao aborto espontâneo recorrente nas pacientes atendidas no Ambulatório de Aborto Recorrente do Centro de Atenção Integral à Saúde da Mulher (CAISM) da Universidade Estadual de Campinas (UNICAMP), no período de março de 1993 a março de 1997. A população atendida neste ambulatório é geralmente de baixa renda, chegando por encaminhamentos feitos dentro da própria UNICAMP ou de profissionais de todo o Brasil.

\section{Pacientes e Métodos}

Foi realizado um trabalho retrospectivo no qual foram revistos os prontuários de 175 mulheres com história de três ou mais abortos espontâneos consecutivos e/ou dois abortos e idade acima de 35 anos, atendidas no Ambulatório de Aborto Recorrente do CAISM/UNICAMP. Todas as pacientes haviam sido submetidas à investigação da etiologia segundo protocolo e foram divididas em cinco grupos conforme a etiologia associada ao aborto recorrente: genética, endócrina, infecciosa, uterina e imunológica, sendo que a mesma paciente poderia pertencer concomitantemente a dois ou mais grupos de etiologia.

A etiologia genética foi avaliada por meio do cariótipo do casal. A etiologia uterina foi avaliada mediante histerossalpingografia e/ou histeroscopia. A histerossalpingografia foi considerada anormal quando foram detectadas as seguintes alterações: falha de enchimento, alteração anatômica da cavidade, uma ou duas trompas tortuosas, impérvias ou malformadas, alteração anatômica do colo uterino ou sugestão radiológica de incompetência istmo-cervical, vista, à histerossalpingografia, como imagem em funil no canal cervical, com ou sem anomalias uterinas associadas. Nestes casos, as pacientes eram encaminhadas para histeroscopia para confirmação do diagnóstico e/ ou tratamento, quando possivel.

A etiologia hormonal foi estudada com o uso de dosagens seriadas de progesterona na segunda fase do ciclo menstrual e biópsia de endométrio entre o $22^{\circ}$ e $24^{\circ}$ dias do ciclo. A função tiroidiana foi avaliada pela dosagem de T3, T4 e TSH. A pesquisa de diabetes mellitus foi feita por meio da determinação da glicemia de jejum.

A dosagem seriada de progesterona foi feita naquelas pacientes que, por algum motivo, não tiveram possibilidade de realizar a biópsia de endométrio. Foram considerados alterados: progesterona abaixo de $21 \mathrm{nmol} / 1$ na fase lútea e/ou a 
defasagem de mais de dois dias entre a data indicada pelo resultado anátomo-patológico e a data da coleta da biópsia de endométrio, T3 acima de $200 \mathrm{ng} \%$ ou abaixo de 80 ng\%, T4 acima de 14,1 ng\% ou abaixo de 5,1 ng\%, TSH acima de 6,12 mUI/ $\mathrm{ml}$ ou abaixo de $0,34 \mathrm{mUI} / \mathrm{ml}$ e glicemia de jejum acima de $110 \mathrm{mg} / 100 \mathrm{ml}$.

A etiologia infecciosa foi investigada com pesquisa para Chlamydia e micoplasma na secreção cérvico-uterina, exames sorológicos para sífilis, toxoplasmose, citomegalovirus, listeriose e brucelose. O crescimento de Chlamydia ou micoplasma na cultura de secreção foi considerado positivo. As sorologias foram consideradas positivas na presença de IgM ou, no caso da toxoplasmose, alteração de duas titulações para mais ou para menos na IgG com um intervalo de 15 dias.

A investigação da etiologia imunológica foi dirigida à subdivisão em dois grupos: auto-imune e aloimune. A avaliação auto-imune incluiu a pesquisa de fator antinúcleo, anticorpos anti-DNA, pesquisa de células LE, anticorpos contra ribonucleoproteínas (anti-Ro e anti-La), anticorpo anticardiolipina e anticoagulante lúpico. A pesquisa do fator aloimune foi feita pela cultura mista unidirecional de linfócitos (CML), com identificação no soro materno de fator inibidor da resposta celular contra linfócitos paternos, e pela prova cruzada por reação de microlinfocitotoxicidade (X-M). A prova foi considerada positiva quando a porcentagem de inibição da resposta celular materna contra linfócitos paternos foi inferior a $50 \% \mathrm{e} / \mathrm{ou}$ o X-M foi negativo, indicando ausência de anticorpos maternos anti-HLA contra antígenos paternos na superficie dos linfócitos.

\section{Resultados}

A média de idade das pacientes foi de 22,03 anos, com variação de 21 a 42 anos. O número de gestações anteriores ao tratamento foi em média de 2,6, variando de 2 a 12 . O número médio de abortos anteriores foi de 2,3, variando de 2 a 12 .

Os resultados do protocolo de investigação completo não foram obtidos para todas as pacientes. O número de pacientes que obtiveram cada resultado é citado nas tabelas.

Das pacientes avaliadas, $88,6 \%$ tinham prova cruzada negativa ( $\mathrm{n}=140$ ) e $81,9 \%$ tinham inibição na cultura mista de linfócitos menor que $50 \%(n=127)$. Elas foram consideradas portadoras de fator aloimune.

Entre os auto-anticorpos avaliados, o anticardiolipina foi encontrado com maior freqüência $(3,8 \%)$, como se observa na Tabela 1 .
Tabela 1 - Distribuição de pacientes com aborto espontâneo recorrente segundo o resultado da pesquisa de auto-anticorpos.

\begin{tabular}{lcrrr}
\hline Anticorpo & \multicolumn{2}{c}{ Positivo } & \multicolumn{2}{c}{ Negativo } \\
& $\mathbf{n}$ & $\%$ & $\mathbf{n}$ & $\%$ \\
\hline Anti-DNA & 2 & 1,4 & 136 & 98,6 \\
Fator antinúcleo & 5 & 3,4 & 144 & 96,6 \\
Fator anticoagulante lúpico & 3 & 3,2 & 92 & 96,8 \\
Anticorpo anticardiolipina & 5 & 3,8 & 125 & 96,2 \\
Células LE & 0 & & 100 & 100,0 \\
Anti-Ro & 1 & 1,8 & 55 & 98,2 \\
Anti-La & 0 & & 51 & 100,0 \\
\hline
\end{tabular}

A investigação dos fatores hormonais mostrou que $21,2 \%$ das pacientes avaliadas $(n=66)$ tinham biópsia de endométrio alterada, ao passo que $15,4 \%$ das 39 pacientes avaliadas por meio da dosagem seriada de progesterona mostraram resultados anormais (Tabela 2).

Tabela 2 - Resultados da investigação de deficiência lútea, função tiroidiana e diabetes mellitusem pacientes com aborto recorrente.

\begin{tabular}{lccrr}
\hline Investigação hormonal & \multicolumn{2}{c}{ Normal } & \multicolumn{2}{c}{ Anormal } \\
& $\mathbf{n}$ & $\%$ & $\mathbf{n}$ & $\%$ \\
\hline Progesterona sérica & 33 & 84,6 & 6 & 15,4 \\
Biópsia do endométrio & 52 & 78,8 & 14 & 21,2 \\
T3, T4 e TSH & 70 & 97,2 & 2 & 2,8 \\
Glicemia de jejum & 82 & 98,8 & 1 & 1,2 \\
\hline
\end{tabular}

O cariótipo foi normal em 85 de 87 pacientes $(97,7 \%)$ e o masculino em 82 de 84 parceiros investigados $(97,6 \%)$.

A investigação de incompetência istmocervical por histerossalpingografia revelou que $22,8 \%$ das 79 pacientes avaliadas apresentaram sinais radiológicos compativeis com este fator.

A Tabela 3 mostra que, na pequisa do fator infeccioso, o Mycoplasma hominis foi o agente encontrado com maior freqüência $(11 \%$ de 36 pacientes avaliadas).

Tabela 3 - Resultados da investigação de síflis, citomegalovirose, toxoplasmose, listeriose brucelose e pesquisa de Chlamidia trachomatis e Mycoplasma hominis na secreção vaginal em pacientes com aborto recorrente.

\begin{tabular}{lrrrr}
\hline \multirow{2}{*}{ Agente infeccioso } & \multicolumn{2}{c}{ Positivo } & \multicolumn{2}{c}{ Negativo } \\
& $\mathbf{n}$ & $\%$ & $\mathbf{n}$ & $\%$ \\
\hline Treponema pallidum & 1 & 0,9 & 106 & 99,1 \\
Citomegalovirus & 2 & 3,8 & 51 & 96,2 \\
Toxoplasma gondii & & 0 & 92 & 100,0 \\
Listeria monocytogenes & 2 & 4,3 & 45 & 95,7 \\
Brucellae sp & 1 & 1,6 & 63 & 98,4 \\
Chlamydia trachomatis & & 0 & 36 & 100,0 \\
Mycoplasma hominis & 4 & 11,1 & 32 & 88,9 \\
\hline
\end{tabular}




\section{Discussão}

As alterações associadas ao aborto recorrente têm sido extensamente discutidas na literatura mundial ${ }^{13}$. Há grande dificuldade de se associar os achados clínicos e as alterações laboratoriais com a probabilidade de nova interrupção. Entretanto, as alterações genéticas, hormonais, infecciosas, uterinas e imunológicas têm sido relatadas como fatores que predispõem ao aborto recorrente.

Iniciamos em março de 1993 a investigação sistemática de fatores etiológicos associados ao aborto recorrente conforme protocolo descrito. Este incluiu a avaliação das alterações imunológicas descritas como associadas aos quadros de aborto, com ênfase a alterações auto-imunes, representadas pela presença dos anticorpos anticardiolipina, anticoagulante lúpico, anti-DNA, fator antinuclear e alterações aloimunes, investigadas pela reação de prova cruzada e cultura mista de linfócitos.

Nossos resultados revelam que o fator aloimune foi, sem dúvida, o mais encontrado nos casais avaliados. Não há evidência científica direta de que fatores aloimunes desempenhem papel nas perdas gestacionais humanas ${ }^{13}$, mas vários testes imunológicos têm sido investigados como marcadores clínicos potenciais. Nesta categoria enquadram-se o X-M e a CML. Vários tratamentos têm sido desenvolvidos a partir desta hipótese, como a imunização com linfócitos paternos ou de doadore ${ }^{14} \mathrm{e}$, mais recentemente, a utilização de imunoglobulina humana endoveno$\mathrm{sa}^{15,16}$.

A incompetência istmo-cervical foi definida por McDonald ${ }^{17}$ como a inabilidade em manter uma gravidez intra-uterina devida a uma fragilidade inerente ou adquirida do colo uterino. Foi encontrada em 13\% das pacientes estudas por Stray-Pedersen e Stray-Pedersen ${ }^{11}$. Fizemos o diagnóstico de incompetência istmo-cervical em $22,8 \%$ de 79 pacientes estudadas até o momento. Esta cifra é mais elevada que a descrita na literatura mesmo em outras séries publicadas e, provavelmente, se deve à sistemática adotada de se investigar todas as pacientes mediante exame radiológico contrastado e com revisão dos laudos por um dos investigadores, exceto se as mesmas engravidassem antes que fosse possivel a realização do exame.

A disfunção tiroideana é tradicionalmente apontada como uma causa infreqüente de aborto recorrente, exceto quando há descompensação clínica. Atualmente a presença de alterações autoimunes dirigidas contra a tiróide ou aos hormôni- os tiroideanos apresenta melhor correlação como marcador de mau prognóstico para a interrupção recorrente de gravidez. Stray-Pedersen e StrayPedersen $^{11}$ diagnosticaram hipertiroidismo em uma mulher e hipotiroidismo em três mulheres, de um total de 195 estudadas. Neste estudo detectamos uma com hipertiroidismo e uma com hipotiroidismo entre 72 pacientes avaliadas. Mesmo assim estas pacientes já referiam diagnóstico e tratamento prévio à admissão ao estudo. Apesar da baixa freqüência, consideramos que as disfunções da tiróide devem ser incluídas na avaliação dos casais com aborto recorrente.

Diabetes mellitus é outra alteração freqüentemente questionada como tendo relação com o aborto recorrente. Em nossa série foi encontrada apenas uma paciente com esta doença, entre 83 estudadas. Este índice está de acordo com outras séries vistas na literatura ${ }^{1,11}$. Desse modo, parece razoável acreditar que o diabetes possa ter baixa relevância para os quadros de aborto recorrente. Porém, pela gravidade de sua evolução quando associado à gravidez, não deve deixar de ser investigado neste grupo de pacientes.

O defeito da fase lútea (DFL) é definido como a baixa produção de progesterona detectada por dosagens seriadas na fase lútea ou biópsia de endométrio defasada em dois dias em relação aos dados clínicos do ciclo menstrual ${ }^{18}$. Estes testes avaliam a paciente fora do ciclo gravídico-puerperal e inferem, a partir daí, o comportamento da produção hormonal durante o ciclo concepcional. Isto se aplica porque há grande dificuldade de se realizar avaliação da função lútea acuradamente no decorrer da gestação. No nosso protocolo utilizamos a dosagem de progesterona e/ou a biópsia de endométrio, sendo esta última de nossa preferência para firmar o diagnóstico de DFL. Conforme referido na literatura, a dosagem seriada de progesterona tem baixa sensibilidade para detecção de defeitos na maturação do endométrio ${ }^{19}$. A biópsia de endométrio é considerada essencial na avaliação do DFL, apesar de todas as controvérsias existentes, porque pode sugerir a presença de outras alterações endometriais, tais como endometrite, sinéquias, miomatose e tuberculose. Além disso, funciona como um bioensaio para avaliar os efeitos da progesterona no tecido endometrial, fornece material para a dosagem de receptores, e revela uma possivel disparidade glândulaestroma no desenvolvimento do tecido e possiveis alterações no sítio de implantação ${ }^{20}$. Em nosso estudo foram detectadas alterações na dosagem de progesterona na fase lútea em $15,4 \%$ das 39 pacientes avaliadas com este método. A baixa proporção de mulheres que completou este estudo demonstra a dificuldade em se conseguir que uma 
paciente venha ao laboratório quatro a cinco vezes no decorrer de um ciclo menstrual. A biópsia de endométrio, considerada o padrão-ouro para o diagnóstico de defeito da fase lútea, identificou $21,2 \%$ de exames anormais entre as 66 pacientes estudadas. Este índice diagnóstico está de acordo com o referido na literatura, que varia de 23 a $70 \%{ }^{19}$, mas abaixo dos índices esperados em relação aos diagnósticos de alterações ístmicocervicais ${ }^{17}$. Mais uma vez isto pode estar relacionado à sistemática de investigação radiológica descrita acima, que eleva nossos índices de diagnóstico de alterações do colo uterino.

Apesar de as infecções do trato reprodutivo terem sido apontadas como possivel associação com abortos de repetição, o assunto ainda permanece controverso ${ }^{21}$. Para que isso fosse correto o microorganismo teria de estar presente por um grande período de tempo, produzir sintomas maternos mínimos para ter escapado ao diagnóstico e tratamento, e ganhar acesso ao compartimento fetal para causar a perda, tanto pela infecção do tecido fetal como pelo estímulo de uma resposta inflamatória. Em nosso estudo, o micoplasma (Ureaplasma urealitycum e Mycoplasma hominis) foi identificado em $11,1 \%$ dos 36 casos pesquisados e a Listeria monocytogenes identificada em 4,3\% de 47 pacientes estudadas. Em relação ao Mycoplasma nossos dados se aproximam dos relatados em literatura $^{1,11}$. De qualquer maneira as infecções não parecem representar um conjunto importante de afecções no grupo de casais estudados.

Entre os fatores auto-imunes destaca-se a chamada sindrome antifosfolipide, que se define por quadro de aborto recorrente, episódios trombóticos e a presença de um "anticoagulante" circulante e/ou anticorpos anticardiolipina (ACA), principalmente em mulheres jovens aparentemente saudáveis ${ }^{22}$. Estas pacientes têm presente na circulação o anticorpo ACA (entre outros fosfolipides) principalmente e/ou um tempo de tromboplastina parcial ativada (TTPA) prolongado, que é a maneira simplificada de se investigar a presença do anticoagulante lúpico. Em nosso estudo verificou-se a presença do ACA em apenas 3,8\% de 130 pacientes estudadas e o TTPA se mostrou alargado em 3,2\% de 95 pacientes. A presença do anticoagulante lúpico nas pacientes com TTPA alargado foi confirmada por dois outros testes, o kaolin clotting time e o Russel viper venom test. Em estudo comparativo entre pacientes férteis e com aborto recorrente, Couto et al. ${ }^{23}$ encontraram a presença de anticardiolipina em 7,7\% das pacientes com aborto e $8,7 \%$ das pacientes férteis. Esta diferença em relação à literatura, também encontrada no grupo de pacientes avaliadas neste trabalho, provavelmente se deve a diferenças raciais ou à reatividade imunológica diferente daquela encontrada nos grupos anglo-saxões descritos em outros artigos. Em pacientes de clinica privada a freqüência de anticorpos antifosfolipídicos em casais portadores de aborto recorrente, procedentes de várias regiões do Brasil, é a mesma descrita neste grupo seguido em nivel universitário, o que não justifica a diferença entre este grupo e aqueles de nivel social mais elevado.

O fator antinuclear (FAN) é outro anticorpo associado aos abortos de repetição ${ }^{24}$. Xu et al. ${ }^{25}$ mostraram correlação positiva entre o FAN e abortos recorrentes, com positividade em $40 \%$ dos casos com abortos repetidos sem etiologia aparente e em 53\% daqueles que tinham algum outro tipo de explicação. Verificamos que apenas $3,4 \%$ das pacientes de um total de 149 estudadas apresentaram este tipo de anticorpo. Mais uma vez, a baixa reatividade do grupo seguido para auto-anticorpos pode ter ocorrido por diferenças raciais, sendo que a nossa população apresenta menor propensão para o desenvolvimento de fenômenos auto-imunes que aqueles grupos com aborto habitual descritos na literatura. Há de se levar em conta o fato de que alguns autores consideram muito baixos os pontos de corte na classificação de positividade para determinado autoanticorpo, o que pode também influenciar no resultado obtido em termos de freqüência. Consideramos como positivo em nosso estudo aqueles resultados com títulos acima de $1 / 40$ e padrão fragmentoso à imunofluorescência indireta, e mesmo assim nossos resultados estão abaixo dos referidos na literatura.

As alterações genéticas são sempre as primeiras a serem investigadas e lembradas pelos clínicos quando estão avaliando pacientes portadoras de aborto recorrente. Já foi observado que a freqüência de anomalias cromossômicas detectadas nos produtos de aborto chega a niveis acima de $50 \%$, conforme classicamente proposta por Boué et $\mathrm{al}^{26}$. na França, na década de 70 . Contudo, estas cifras não são observadas quando se avaliam os produtos conceptuais dos casais que apresentam perdas recorrentes. A avaliação genética por cariótipo do casal com aborto recorrente está instituída como rotina na maioria dos serviços que os atendem. Há unanimidade, contudo, no indice de resultados anormais encontrados neste grupo que não ultrapassa 4\% dos casais, quando considerados os resultados do marido ou da mulher ${ }^{27}$.

O estudo das possiveis associações etiológicas em pacientes com aborto recorrente é ainda controverso. A investigação realizada nos casais analisados é dividida em cinco grupos de alterações diferentes e permite identificar positivamente um 
grande número delas, com ênfase especial para os resultados de exames relativos à aloimunidade, alterações do colo uterino e fase lútea deficiente. Recomenda-se aos serviços que pesquisem casais com aborto recorrente que sigam protocolos semelhantes a fim de que possam oferecer tratamento adequado a este grupo de pacientes.

\section{SUMMARY}

Purpose: to identify recurrent spontaneous abortionassociated factors.

Subjects: one hundred seventy-five outpatients were investigated from March 1993 to March 1997 at the "Ambulatório de Aborto Recorrente CAISM/UNICAMP". All of them had had three or more consecutive spontaneous abortions and/or two abortions and were 35 years or more old .

Methods: the investigation protocol included: couple's karyotype; hysterosalpingography, serial plasma progesterone levels and/or endometrial biopsy; toxoplasmosis, listeriosis, brucelosis, lues and cytomegalovirus serum tests; Chlamydia trachomatis and Mycoplasma hominis cultures of cervical discharge; TSH and thyroid hormone levels; fasting glucose; autoantibody panel, anti-HLA antibody search by microlymphocytotoxicity crossmatch and one-way mixed lymphocyte culture with inhibitor factor detection. Husband's evaluation included: physical evaluation, lues, Chagas' disease, $B$ and Chepatitis and AIDS serum tests, microlymphocytotoxicity crossmatch and one-way mixed lymphocyte culture with inhibitor factor detection.

Results: alloimmune etiology was the most frequently found factor ( $86.3 \%$ of studied patients), represented by negative crossmatch and one-way mixed lymphocyte culture with inhibitor factor below $50 \%$. The second most frequently found factor was cervical incompetence (22.8\%), followed by hormonal factor $(21.2 \%)$, mainly represented by luteal insufficiency. Some patients were found to have more than one etiologic factor.

Conclusion: the investigation of recurrent spontaneous abortion-associated factors must include alloimmune etiology. Most cases will remain unexplained without this investigation.

KEY WORDS: Abortion. Antiphospholipid antibodies. Lymphocyte. Cervical incompetence.

\section{Referências}

1. Harger JH, Archer DF, Marchese SG, MuraccaClemens M, Garver KL. Etiology of recurrent pregnancy losses and outcome of subsequent pregnancies. Obstet Gynecol 1983; 62:574-81.
2. Costa HLFF, Moura MD, Ferriani RA, Anceschi MIS, Barbosa JE. Prevalence of anti-cardiolipin antibody in habitual aborters. Gynecol Obstet Invest 1993; 36:221-5.

3. Hertz-Picciotto I, Samuels SJ. Incidence of early loss in pregnancy. N Eng J Med 1988; 319:1483-4.

4. Coulam CB. Epidemiology of recurrent spontaneous abortion. Am J Reprod Immunol 1991; 26:23-7.

5. Warburton D, Strobino B. Recurrent spontaneous abortion. In: Bennett MJ, Edmonds DK, editores. Spontaneous and Recurrent Abortion. Oxford: Blackwell Scientific; 1987. p.193-202.

6. Csapo AI, Pulkkinen MO, Wiest WG. Effects of luteectomy and progesterone replacement therapy in early pregnant patients. Am J Obstet Gynecol 1973; 115:759-65.

7. Botella LJ. The endometrium in repeated abortion. Int J Fertil 1962; 7:147-8.

8. Costa HLF. Autoimunidade e perda conceptual [tese]. Ribeirão Preto: Universidade de São Paulo; 1994.

9. Daly DC, Walters CA, Soto-Albors CE, Riddick DH. Endometrial biopsy during treatment of luteal phase defects is predictive of therapeutic outcome. Fertil Steril 1983; 40:305-10.

10.Boué A. Spontaneous abortions and cytogenetic abnormalities. In: Behrman SJ, Kistner RW, Patton GW, editores. Progress in Infertility. $3^{\text {rd }}$ ed. Boston: Little, Brown and Company; 1988. p.783-5.

11.Stray-Pedersen B, Stray-Pedersen S. Etiologic factors and subsequent reproductive performance in 195 couples with a prior history of habitual abortion. Am J Obstet Gynecol 1984; 148:140-6.

12. Carp HJA, Toder V, Mashiach S, Nebel L, Serr DM. Recurrent miscarriage: a review of current concepts, immune mechanisms and results of treatment. Obstet Gynecol Surv 1990; 45:657-69.

13. Stirrat GM. Recurrent spontaneous abortion. In: Coulam CB, Faulk WP, McIntyre JA, editores. Immunological Obstetrics. London: Norton Medical Books; 1992. p.357-60.

14.Takakuwa K, Goto S, Hasegawa I, et al. Result of immunotherapy on patients with unexplained recurrent abortion: a beneficial treatment for patients with negative blocking antibodies. Am J Reprod Immunol 1990; 23:37-41.

15.Ruiz JE, Kwak JY, Baum L, et al. Intravenous immunoglobulin inhibits natural killer cell activity in vivo in women with recurrent spontaneous abortion. Am J Reprod Immunol 1996; 35:370-5.

16.Barini R, Couto E, Ribeiro ST, Leiber SR, Batista SC, Pinto e Silva JL. Abortamento recorrente de causa imunológica: avaliação de um protocolo de investigação e tratamento. Rev Bras Ginecol Obstet 1998; 20:83-9. 
17. McDonald IA. Cervical incompetence as a cause of spontaneous abortion. In: Bennett MJ, Edmonds DK, editores. Spontaneous and Recurrent Abortion. Oxford: Blackwell Scientific; 1987. p.168-73.

18.Jones GES. Some newer aspects of the management of infertility. JAMA 1949; 147:1123-5

19.Fritz MA. Inadequate luteal function and recurrent abortion: diagnosis and treatment of luteal phase deficiency. Semin Reprod Endocrinol 1988; 6:12931.

20.Wanderley MS, Ferriani RA, Moura MD. Defeitos da fase lútea: há algo de novo? Femina 1998; 26: 495-8.

21.Watts DH, Eschenbach DA. Reproductive tract infections as a cause of abortion and pre-term birth. Semin Reprod Endocrinol 1980; 6:205-7.

22.Hughes GR. Thrombosis, abortion, cerebral disease and lupus anticoagulant. Br Med J (Clin Res Ed) $1983 ; 287: 1088-9$.
23. Couto E, Barini R, Pinto e Silva JL, Moraes DRLP, Carvalho LMF. Anticardiolipin antibody in recurrent spontaneous aborting and fertile women. São Paulo Med J 1998; 116:1760-5.

24.Garcia-De La Torre I, Hernandez-Vazquez L, AnguloVazquez J, Romero-Ornelas A. Prevalence of antinuclear antibodies in patients with habitual abortion in normal and toxemic pregnancies. Rheumatol Int 1984; 4:87-9.

25.Xu L, Chang V, Murphy A, et al. Antinuclear antibodies in sera of patients with recurrent pregnancy wastage. Am J Obstet Gynecol 1990; 163:1493-7.

26.Boué J, Boué A, Lasar P. Retrospective and prospective epidemiological studies of 1500 karyotyped spontaneous human abortions. Teratology 1975; 12:11-26.

27.Olson SB, Magenis RE. Cytogenetic aspects of recurrent pregnancy loss. Semin Reprod Endocrinol 1988; 6:191-4. 